\title{
A Study on the Spontaneous Representation of Animals in Young Children's Drawings of Plant Life
}

\author{
José Domingo Villarroel ${ }^{1, *(\mathbb{D})}$, Alvaro Antón ${ }^{1}{ }^{(\mathbb{D})}$, Daniel Zuazagoitia ${ }^{2}$ and Teresa Nuño ${ }^{1}$ \\ 1 Faculty of Education Bilbao, University of the Basque Country, UPV/EHU, 48940 Lejona, Spain; \\ alvaro.anton@ehu.eus (A.A.); teresa.nuno@ehu.eus (T.N.) \\ 2 Education and Sport Faculty, University of the Basque Country, UPV/EHU, 48940 Lejona, Spain; \\ daniel.zuazagoitia@ehu.eus \\ * Correspondence: txomin.villarroel@ehu.eus; Tel.: +34-946-01-7503
}

Received: 7 March 2018; Accepted: 26 March 2018; Published: 28 March 2018

\begin{abstract}
Previous research indicates that complex biological concepts may be successfully introduced in preschool age, provided that suitable educational interventions are designed for the initial stages of education. In this regard, there is evidence that a basic understanding of the issue of the ecological interactions among organisms may be achieved in the preschool years. With this in mind, this research project tests the assumption that recognising the fact that plants and animals are not isolated creatures, but live engaged in constant interactions in nature, may begin to be understood in early education. To that end, this study examines the content of free drawings that a sample of 328 children aged four to seven years of age, undertook when explaining their understanding of plant life. Data regarding the type and frequency of the depictions of animals found in the children's graphic explanations on flora is collected and read in conjunction with participants' gender and academic level. The results show that a substantial proportion of the children in the sample spontaneously drew illustrations of animals in their graphic explanations concerning vegetable life and, more significantly, some pictures show plants and animals engaged in clear contact. This is the case, despite the fact that the drawing activity had been focused solely on the issue of plant life and no indication linked to depicting other kinds of living things mentioned during the activity. The conclusions discuss the data collected in connection with the growing number of research projects that study the question of how young children begin to embrace the fundamental biological concepts that pave the way to the understanding of natural phenomena and make the public capable of making responsible choices when it comes to sustainability issues.
\end{abstract}

Keywords: early education; science education; biology; ecology; living things

\section{Introduction}

Life science education has to put significant emphasis on promoting the understanding of the ecological relationships among living things [1]. This is particularly true considering that being aware that organisms interact and coexist within an intricate net of connections is part of the basic ecological comprehension that people need so as to make well-informed choices affecting sustainability matters [2].

In the particular context of early education, some authors raise the question of whether the topic of the ecological relationships among organisms might exceed the educational objectives posed for kindergarten educational programmes [3]. In this regard, there is evidence to support the belief that appropriate educational methods make the introduction of complex biological concepts in early education a success, including such topics as within-species variation [4], natural selection [5], feeding relationships [3,6], and models of ecosystems [7]. 
A key factor that makes educational interventions successful is to have appropriate procedures to assess pupils' knowledge [8]. On this issue, art-based procedures are distinguished by their effectiveness when it comes to looking into young children's development and their learning process, also in the specific field of the comprehension of natural phenomena [9].

Scholars point out two main reasons why this is so. Firstly, drawings seems to be intimately connected with young children's internal thoughts and their interpretation of reality [10-13] and, secondly, drawing activities facilitate spontaneous expressivity and communication in early education, even in the case of children who find it difficult to express themselves through words [14].

Accordingly, the analysis of drawings has provided relevant data regarding the comprehension of a large variety of natural phenomena in early childhood. In this way, children's depictions have been utilised to explore, to name some recent relevant projects, their perceptions of the environment [15]; their understanding of different topics related to plant life [16,17], and animals [18,19]; and, also, to study their comprehension of issues linked to earth sciences [13,20-22], as well as health subjects [23,24].

In addition, the examination of young children's drawings has also been considered to gain insight into their process of grasping the interactions among organisms. Thus, in a study that involves 35 preschool children's drawings, Lauren Madden and Jennifer Liang [25] provide evidence that the children express interactions between plants and animals in their depictions of nature. Furthermore, this study leads to the conclusion that these illustrations become more frequent after the children are involved in specific educational interventions to promote a better understanding of the role that trees have as creatures' habitats. In another significant study concerning a larger sample that also includes children older than eight years of age, Flowers' research group [26] finds that when depicting their understanding of ecosystems, children's representations of interactions among organisms do occur even though this kind of depiction tends not to be very frequent. Not all available studies, by contrast, achieve similar conclusions. Amy Dai [27] examines a limited sample of young children's expressions, including drawings, on the topic of nature and accounts for the fact that no evidence is found in line with the idea that the children might have begun to understand the issue of the interdependency of nature.

Consequently, previous research seems to support the belief that before the age of eight years, children might have begun to develop a basic understanding regarding the interactions occurring among organisms and, more particularly, with regard to those related to plants and animals. Notwithstanding the data that supports this belief, the fact is that not all the evidence collected is coherent with these ideas and, in addition, that the early comprehension of the ecological relationships among organisms, specifically, is a research topic that has not been extensively studied.

Against this background, this study intends to test the assumption that in the drawings that young children, aged 4-7 years old, carry out on the topic of nature, specific pictorial elements may be detected that indicate that children have achieved a basic understanding regarding the issue that organisms are not isolated entities, but live in continual interaction in the environment.

To that end, young children's spontaneous artistic production will be put under examination and any evidence indicating a basic awareness of plant-animal interaction will be investigated.

For that purpose, the following specific objectives are proposed for the study:

(a) Firstly, to examine the content of the drawings undertaken by the children in the sample on the issue of plant life in order to determine the frequency of the depictions of animals in their drawings on this issue, broken down by the types of animals (that is, vertebrate or invertebrate).

(b) Secondly, to look into the representation of animals found in children's illustrations to elucidate whether they express some kind of interaction between plants and animals and, if so, what kind of interactions are displayed.

(c) Finally, the gender and educational level variables will be examined in the sense of considering whether these variables show any relationship with the frequency and type of animals drawn as well as, if applicable, with the expression of interactions between plants and animals. 
The ultimate purpose of the present research project is to provide fresh data on the issue of how young children in early education commence to give sense to the core concepts pertaining to the domain of biology, and, more notably, in this particular study, to the concept of interactions between living things which will play a key role in their understanding of the functioning of the ecosystems.

\section{Method}

\subsection{Sample}

The sample under study includes 328 children in elementary education, 162 girls and 166 boys. Table 1 spells out the distribution of the children in accordance with their educational level and age.

Table 1. Distribution of the children of the sample in accordance with their educational level $(N=328)$.

\begin{tabular}{ccc}
\hline & Age at the Time of the Study & $\%$ \\
\hline First year at Primary Education & $6-7$ & 30.2 \\
\hline \multirow{2}{*}{ Preschool education } & $5-6$ & 27.7 \\
& $4-5$ & 42.1 \\
\hline
\end{tabular}

In order to gather the abovementioned sample, the authors of this paper visited six state-run educational centres in the spring term of 2015. Five of these schools are located in the province of Biscay (Spain) and one of them in the province of Burgos (Spain). The schools' participants in the study were chosen under the criteria of proximity and accessibility to the research team. Three of the educational centres are typically city schools, based in towns with no less than 75,000 citizens. The other three schools are located in rural areas where the population does not exceed 6000 inhabitants. In no case did the distance among the educational centres involved in the study exceed 100 kilometers.

The Ethics Committee for Research on Human Beings of the University of the Basque Country tracked and approved the procedure of the study (CEISH/214/2013/Villarroel Villamor). The board of directors of every school, as well as the families whose children were involved in the study, gave written permission to allow the children to be engaged in the research activity.

\subsection{Data Collection}

The present research project examines the depiction that the children in the sample spontaneously undertook on the topic of plant life.

In this respect, every child individually made an illustration about plants throughout a meeting with one of the members of the research team. The meeting was usually held in a separate space within the classroom or, as an alternative, in an adjacent area to the classroom that had been organised for that purpose.

Prior to the commencement of the individual meetings with the children, a single researcher attended the classroom and introduced the drawing activity to the children. Throughout this initial presentation, the researcher told the kids a story involving a puppet that she or he had brought with them. This story was intended to encourage the children to help the puppet understand more about plants by means of a picture that they could draw later during the interview.

The individual encounter with every child began by leaving the puppet with the child and remembering that the objective of the meeting was to draw a picture about plants so as to help the puppet understand more about plants. Subsequently, the researcher offered the child some pencils and a blank sheet of paper to begin the drawing and when the child expressed that they had finished the drawing, both, the child and the interviewer reviewed the meaning of the pictorial elements displayed. Finally, ten different coloured pens were randomly offered to the child to give colour to the pictures. The individual meeting did not usually take more than fifteen minutes. 
The children received no indication or additional explanation regarding plants, animals, or interactions among them, either in the initial presentation of the activity or throughout the individual meetings.

\subsection{Statistical Procedures}

This study poses a quantitative methodology to examine the drawings under consideration. For this purpose, firstly, children's gender, age, educational level, and their first name were recorded.

Moreover and for the objective of examining the content of the pictures, for every drawing the following information was registered:

(a) Whether or not any pictorial elements related to plant life appeared (for instance, flowers, grass, trees, or vegetables).

(b) Whether or not, at least one vertebrate animal appeared in the drawing. The kind of vertebrate animal drawn in each picture was also registered.

(c) Whether or not, at least one invertebrate animal appeared in the drawing. The kind of invertebrate drawn in each picture was also registered.

(d) Whether or not any interaction between plants and animals can be identified in the drawing. The kind of interaction drawn in each picture was also registered.

Some examples of the drawings studied are presented in the Appendix.

Concerning the statistical procedure, the examination of the association between variables was undertaken by chi-square and Cramer's $\mathrm{V}$ parameter was used to measure the effect size. The significance was set at the 0.05 level.

\section{Results}

The following is the presentation of the outcomes of the study. Firstly, the information regarding the type and frequency of animals depicted by the children in the sample will be introduced. Subsequently, the study of the differences encountered in the analysis of the differences in connection with the independent variables, that is, gender and educational level.

Regarding the first point, the representation of fauna was found in $21.6 \%(N=71)$ of the drawings comprising the sample. In addition, $81.7 \%(N=57)$ of those children who depicted fauna, opted for drawing no more than one single animal. In no drawing were there more than three animals illustrated. In contrast, $92.7 \%(N=304)$ of the children drew at least one example of plants in their drawings. This high frequency related to the illustrations of examples of plants is not a surprise, given that the children were told that the objective of the drawing activity was to express their understanding of plant life.

A more careful consideration of the kind of animals that the children drew reveals that $15.9 \%(N=52)$ of those in the sample drew, at least one vertebrate in their picture and that at least one invertebrate animal was found in $8.5 \%(N=28)$ of the drawings. Table 2 presents the list of the animals that the children of the sample drew.

Table 2. A list of the type of animals drawn by the children of the sample.

\begin{tabular}{cccc}
\hline Invertebrate & & Vertebrate & \\
\hline Snail & Dog & Songbird & Dinosaur \\
Earthworm & Cat & Eagle & Crocodile \\
Beetle & Wolf & Chick & \\
Honeybee & Tiger & Seagull & \\
Butterfly & Lion & Elephant & \\
Ant & Fish & Dolphin & \\
Ladybird & Orca & Rabbit & \\
\hline
\end{tabular}


As for the representation of animals in an unambiguous relationship with plants, 5.8\% $(N=19)$ of the pictures showed at least one animal eating, living, or at rest on a type of plant. Figure 1 presents an example of four representations undertaken by four different children in which the animals represented are in connection with plants (more examples are available in the Appendix Figures A1-A4).

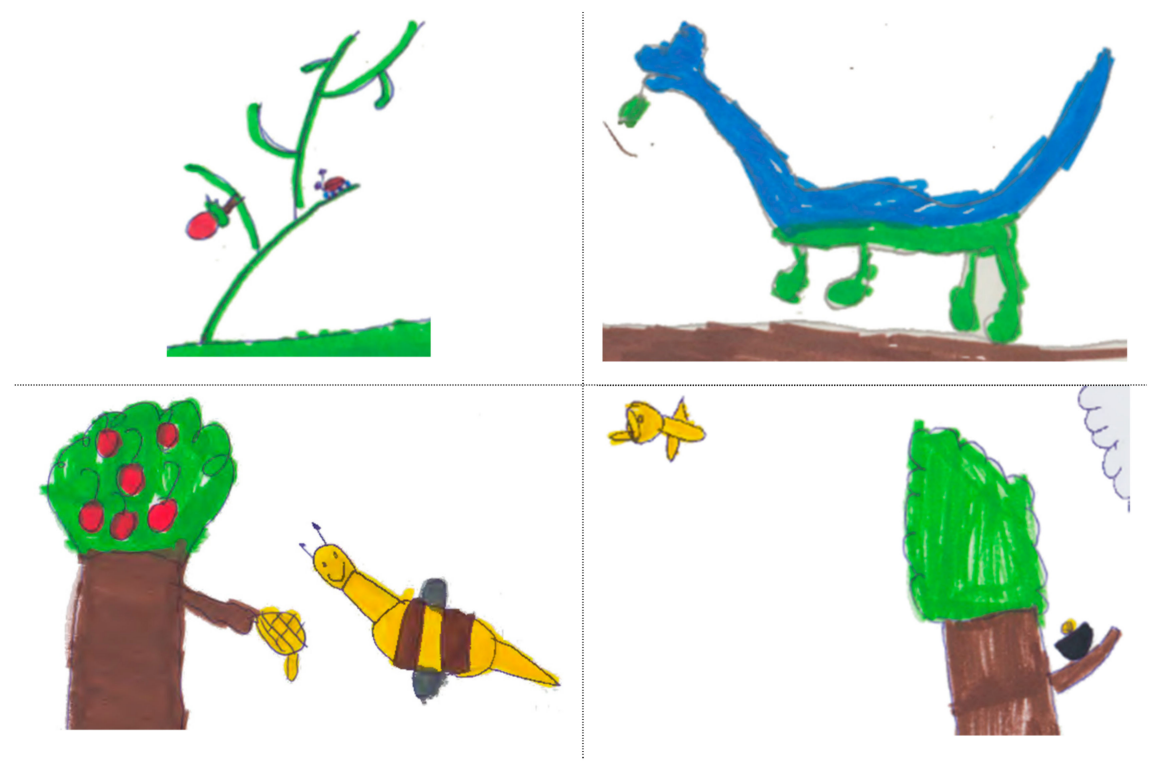

Figure 1. Four samples of illustrations of animals in connection with plants drawn by four different children.

Moving onto the gender-related study, no significant differences were found in connection with the representation of neither vertebrate animals nor invertebrate and, also, no differences were found regarding the depiction of animals in close relationship with plants.

Additionally, when it comes to considering the pictures of children in different educational levels, the frequency of vertebrate animals did not vary substantially. However, the data accounts for the fact that the older children were significantly more prone to display invertebrate animals in their free depiction on flora, as well as drawing animals in connection with plants. Table 3 displays the frequency of the depiction of both invertebrates and animals in connection with plants by the three educational levels considered in the study.

Importantly, the educational level variable shows a medium level of association with the depiction of at least one animal in connection with plants (Cramer's $V=0.24$ ) and approaches a similar level as far as its relationship with the drawing of, at least, one invertebrate animal is concerned (Cramer's $V=0.19$ ).

Table 3. The relative frequency (\%) of the occurrence of the depiction of at least one invertebrate and at least one animal related to plants, spelled out by the educational levels of the children in the sample.

\begin{tabular}{|c|c|c|c|}
\hline Level & Age & $\begin{array}{l}\text { (a) At Least One Invertebrate } \\
\text { Drawn }(N=28)\end{array}$ & $\begin{array}{l}\text { (b) At Least One Animal in } \\
\text { Connection with Plants }(N=19)\end{array}$ \\
\hline $\begin{array}{l}\text { Penultimate year of } \\
\text { Preschool Education }\end{array}$ & $4-5$ & 17.9 & 0 \\
\hline $\begin{array}{c}\text { Finall year of } \\
\text { Preschool Education }\end{array}$ & $5-6$ & 25 & 31.6 \\
\hline $\begin{array}{c}\text { First year of } \\
\text { Primary Education }\end{array}$ & $6-7$ & 57.1 & 68.4 \\
\hline
\end{tabular}




\section{Conclusions}

The aforementioned figures show that one out of five children in the sample spontaneously drew at least one animal in their graphical explanations regarding plant life. Vertebrate animals were the most common illustrations of animals, but it is also significant that almost one in ten of the children depicted one or more invertebrates.

Previous research also indicates that the depiction of animals is a common attribute of young children's representations of nature [28-30]. In addition, it has also been reported that invertebrates may appear in young children's representations of the environment even though this group of animals tend to be misrepresented [31].

However, what seems to be certainly significant in the data provided by this study is the observation that a substantial proportion of young children in the sample spontaneously depict animals to elucidate their knowledge about plant life. Even more importantly, one in fifteen drawings displays at least one animal in an unambiguous relationship with plants (i.e., touching plants, eating them, collecting pollen, or constructing their nests in a tree).

In this regard, it should be noted that young children do not draw without intent. Indeed, their graphical expression is closely linked to their thoughts and feelings $[10,11,32]$ and that is the reason why studying their depictions is considered to be a valuable procedure to better understand their conceptual development $[9,21,33]$.

With this in mind, it seems reasonable to consider that a basic understanding regarding the interactions between plants and animals is the underlying factor that explains why some children in the sample spontaneously introduce animals in their depictions of plant life. This conclusion should be even more relevant in the case of those children who illustrate animals in a clear connection with plants.

Ultimately, this conclusion lends weight to the assumption that considering living things from a relational point of view, in lieu of seeing them as unconnected entities, is not alien to the understanding of nature in early childhood, a fact that has been underscored in only a few studies [34,35]. Connected with these ideas, Madden and Liang's study [25] reports that interactions among livings things become more frequent in young children's verbal and graphical expression as a consequence of their involvement in learning activities aiming to strengthen a relational perspective of nature. This means that the additional level of complexity that entails recognising the environment in terms of the interactions between living things is within the reach of young children before the age of eight. Young children's learning abilities for grasping the foundations of biologically-complex issues has also been underscored by previous research [3-6].

In another development, the outcomes presented in this paper show that age is a relevant issue as far as the early grasping of a relational perspective about plants and animals is involved. Thus, the older the children are, the more frequent their depictions of animals in connection with plants are and, more importantly, this association is considerably marked. Similarly, the drawing of invertebrates appears reasonably linked to the age of the children. These findings are in line with previous research which highlights the fact that age is a key factor in the understanding of natural phenomena $[5,13,16,36]$.

Finally, the lack of gender-related differences found in this study seems to be a significant issue. This observation fits in well with a specific body of research concerning young children's graphical expressions on biological phenomena which accounts for a very weak variation, or even no differences at all, when it comes to comparing girls and boy's drawings on the issues of, for instance, plants [12,37], the sun [13], the structure of trees [17], the distinction of living and non-living things [32,38], ideas about micro-organisms [39], and animals [18], to name but a few.

In contrast, there is also significant evidence that girls in early education tend to perform academically better than their male counterparts [40]. This suggests that the existence of gender gaps, as far as the understanding of biological phenomena is concerned, should not be completely ruled out, as has been stated in other significant studies [18,19,41].

In light of the above, further research is necessary to garner more evidence regarding the issue of the potential differences connected to the gender variable during the process of the grasping of 
natural phenomena in early childhood. Nevertheless, it has been reported that by the age of six years there is a significant turning point as far as the influence that gender stereotypes have on girls' own perceptions regarding their intellectual capacities [42]. In this respect, one might consider that the lack of gender-related differences found in this study could be partly due to the fact that the sample under examination involved a very significant number of children aged 4-6 years; that is to say, an age group in which gender stereotypes might have not begun to have an influence on girls.

In conclusion, this study provides evidence that pictorial elements may be found in early artistic expression that give rise to consider that, well before eight years of age, children begin to comprehend the interdependence among living things in ecosystems. This corollary should serve to bolster teaching methods that offer young children opportunities to reflect on the ecological connections between living things, including human beings; an educational objective that, undoubtedly, should have a significant impact on their environmental thinking.

Acknowledgments: The authors thank the following educational centers for their cooperation and support to undertake this study: Juan Bautista Zabala Eskola (Getxo, The Basque Country, Spain), Geroa Ikastola, (Getxo, the Basque Country, Spain), Colegio San Isidro (Medina de Pomar , Burgos, Spain), Laukizko Lauaxeta Eskola (Laukiz, The Basque Country, Spain), Romo Eskola, (Getxo, The Basque Country, Spain), Gatikako Eskola (Gatika, The Basque Country, Spain), and Getxoko Berritzegunea (Getxo, The Basque Country, Spain). The Ethics Committee for Research on Human Beings of the University of the Basque Country tracked and approved the procedure of the study (CEISH/214/2013/Villarroel Villamor).

Author Contributions: All authors contributed equally to this work.

Conflicts of Interest: The authors declare no conflicts of interest.

\section{Appendix}

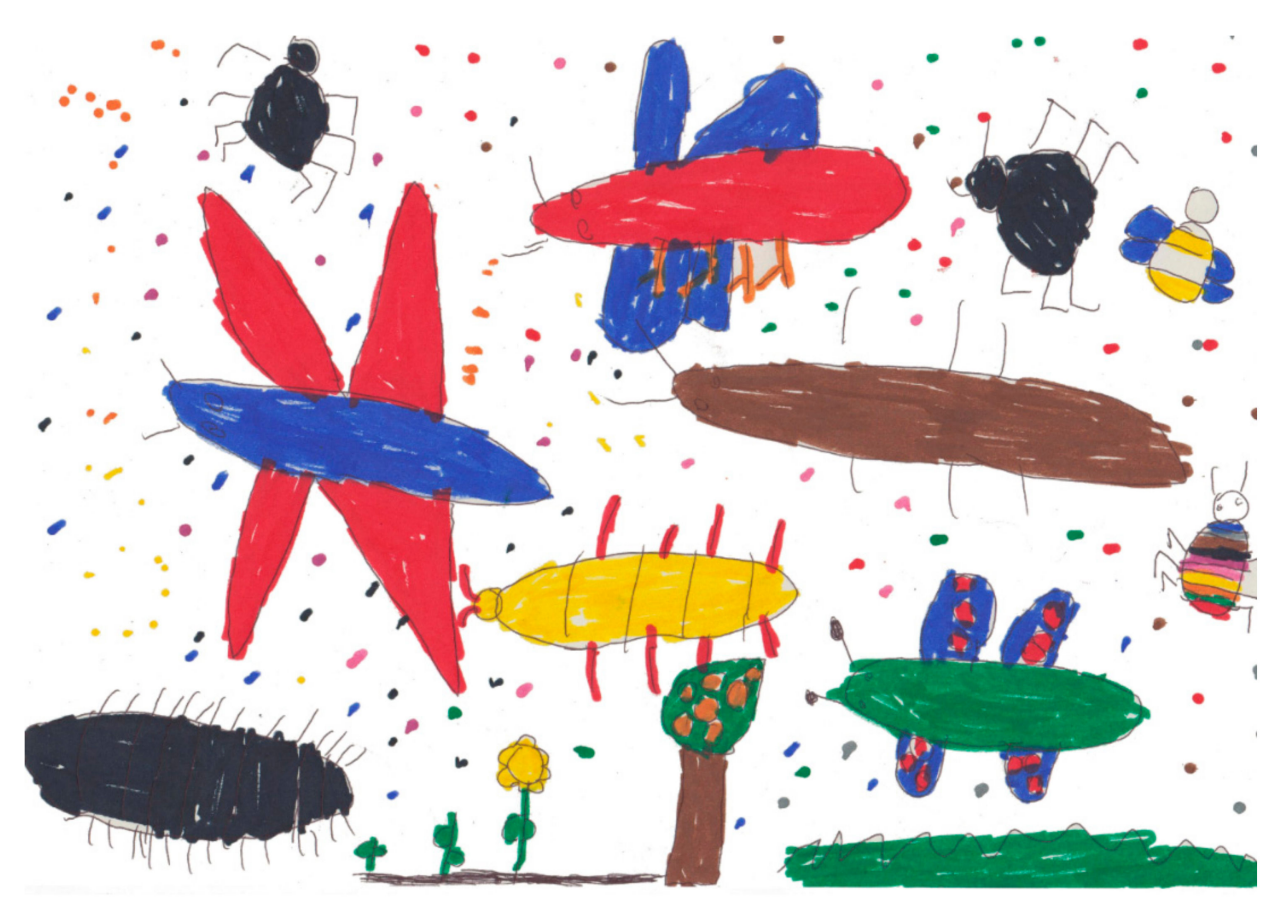

Figure A1. A spontaneous drawing on the issue of plant life carried out by a seven year old child. The picture shows the illustration of some plants (a tree, flowers, and some grass) together with a rich variety of invertebrates. 

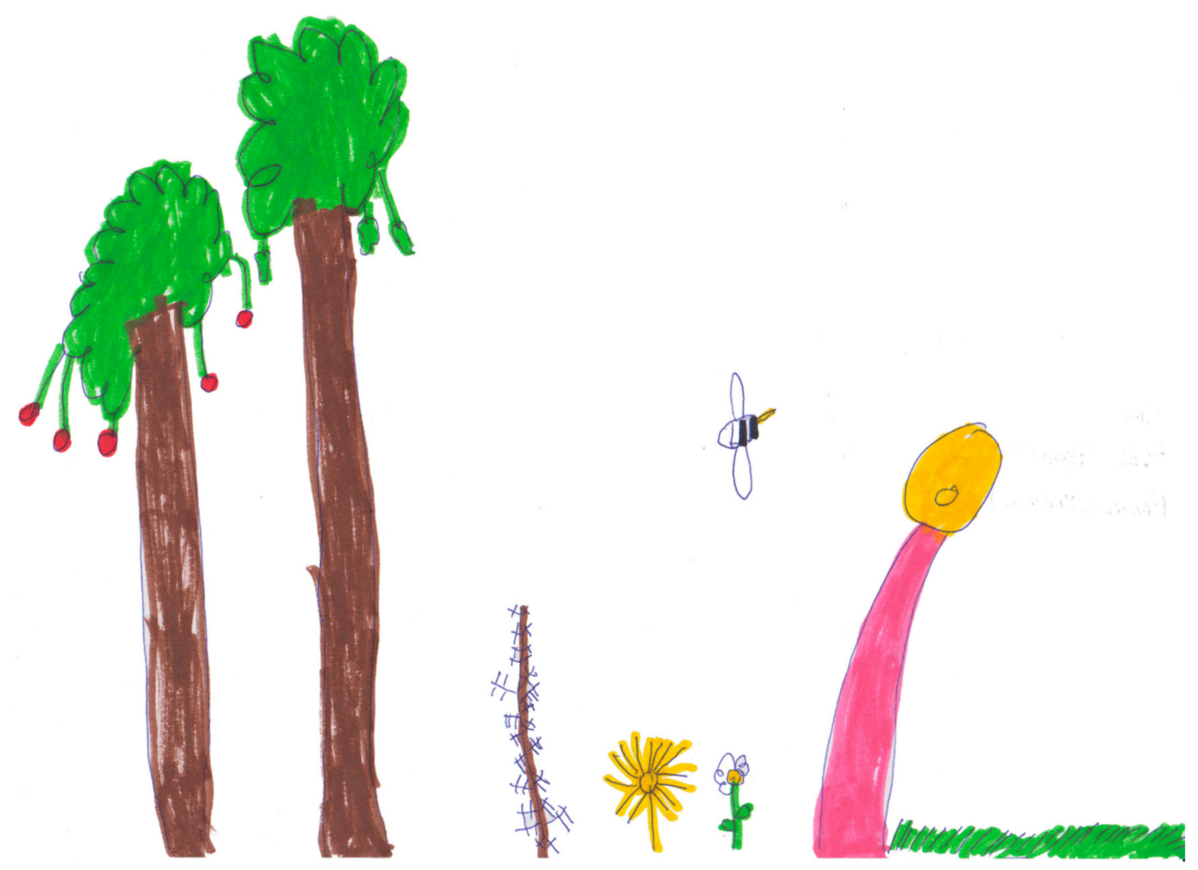

Figure A2. A spontaneous drawing on the issue of plant life carried out by a six year old child. The picture shows a honeybee flying among different plants (trees, flowers, and some grass).

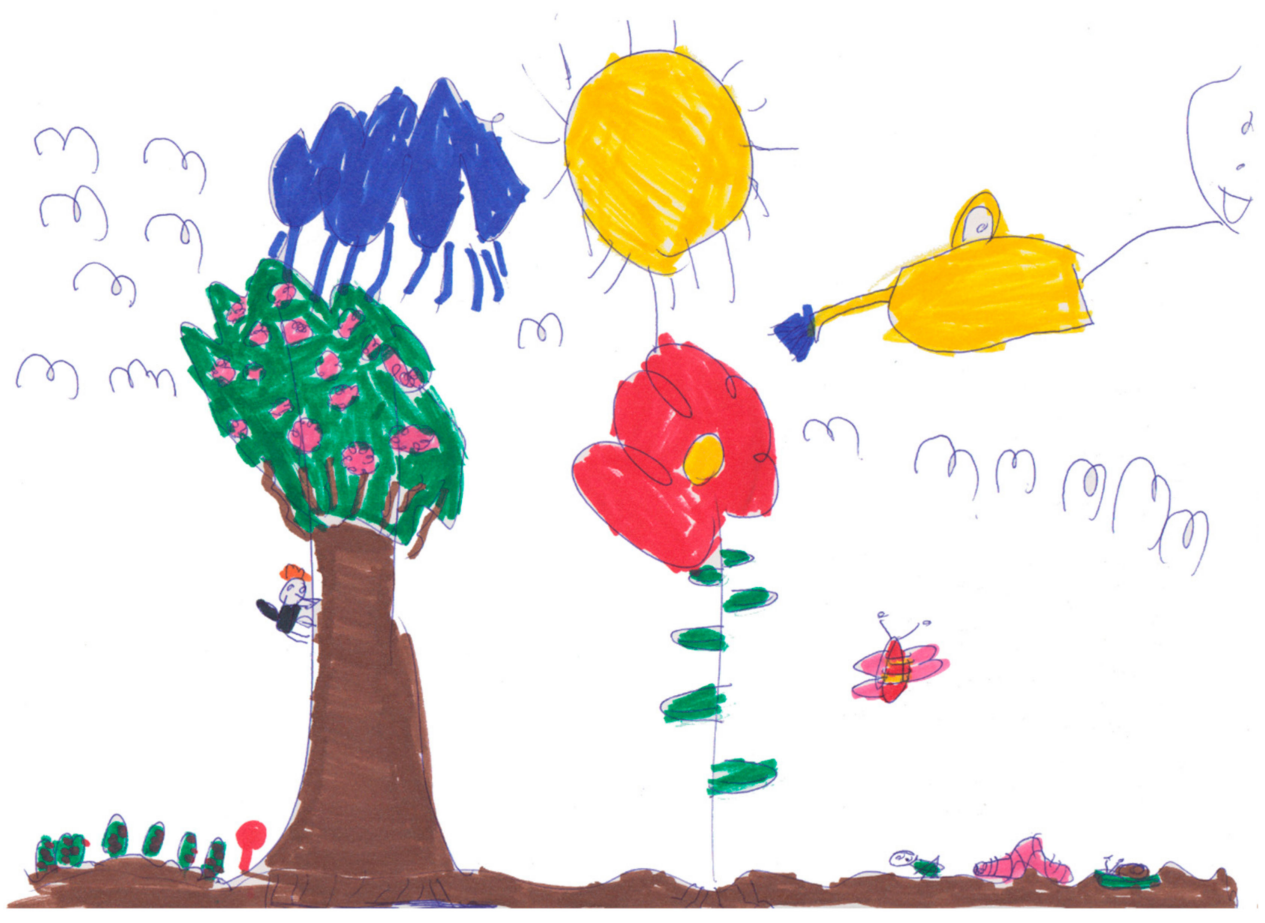

Figure A3. A spontaneous drawing on the issue of plant life carried out by a seven year old child. The picture shows the illustration of a bird pecking a tree trunk and some invertebrates around the plants. 


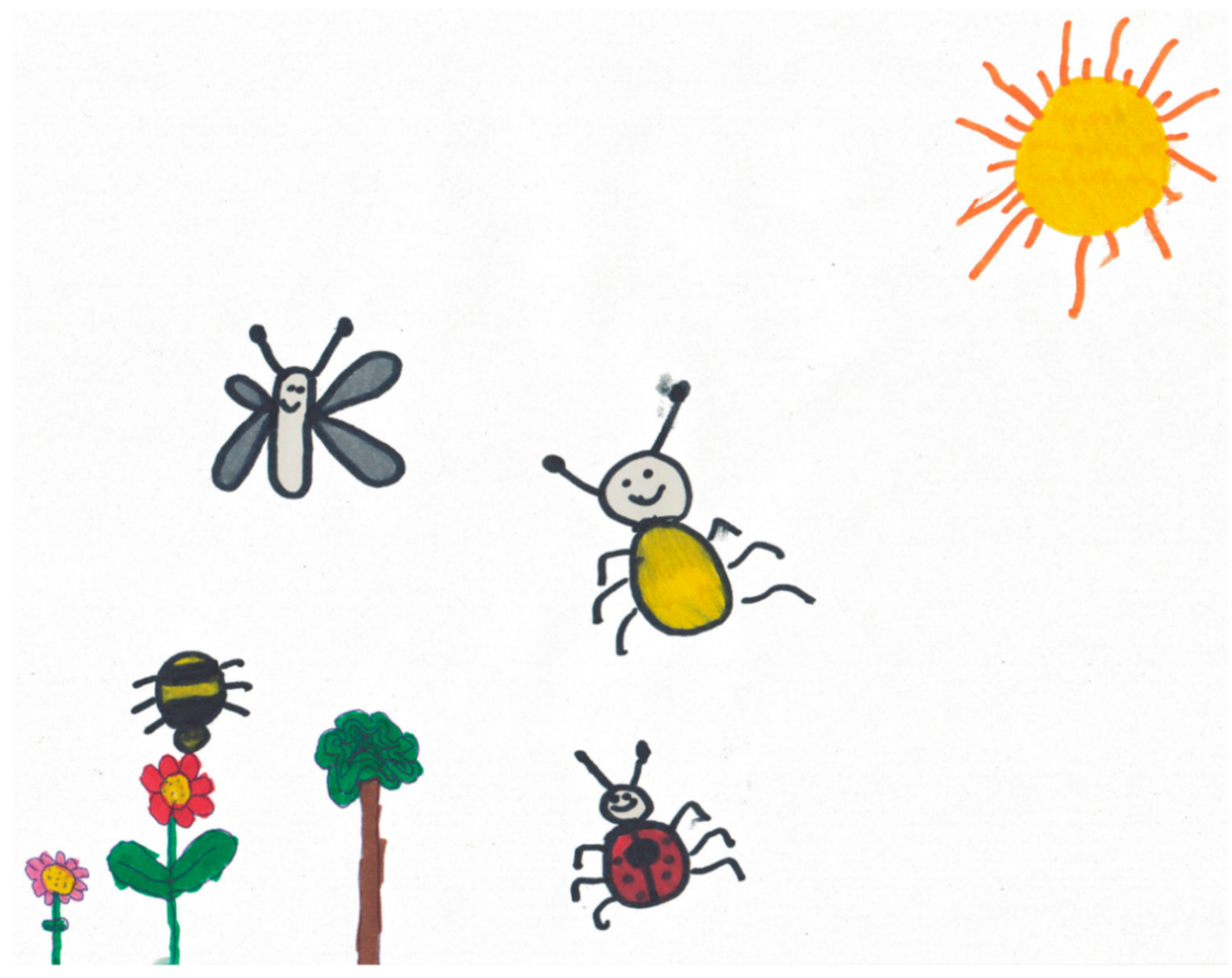

Figure A4. A spontaneous drawing on the issue of plant life carried out by a six year old child. The pictures shows a ladybird eating a flower and other invertebrates around the plants.

\section{References}

1. Ahi, B. The world of plants in children's drawings: The color preference and the effect of age and gender on these preferences. J. Baltic Sci. Educ. 2017, 16, 32-42.

2. Allen, M. Early understandings of simple food chains: A learning progression for the preschool years. Int. J. Sci. Educ. 2017, 39, 1485-1510. [CrossRef]

3. Anderson, J.L.; Ellis, J.P.; Jones, A.M. Understanding early elementary children's conceptual knowledge of plant structure and function through drawings. CBE Life Sci. Educ. 2014, 13, 375-386. [CrossRef] [PubMed]

4. Barraza, L.; Robottom, I. Gaining representations of children's and adults' constructions of sustainability issues. Int. J. Environ. Sci. Educ. 2008, 3, 179-191.

5. Beauregard, C.; Papazian-Zohrabian, G.; Rousseau, C. Making sense of collective identity and trauma through drawing: The case study of a Palestinian refugee student. Intercult. Educ. 2017, 28, 113-130. [CrossRef]

6. Bian, L.; Leslie, S.J.; Cimpian, A. Gender stereotypes about intellectual ability emerge early and influence children's interests. Science 2017, 355, 389-391. [CrossRef] [PubMed]

7. Cainey, J.; Humphrey, L.; Bowker, R. Drawing Experiences in Marine Conservation; Katz, P., Ed.; Drawing for Science Education; SensePublishers: Rotterdam, The Netherlands, 2017; pp. 97-109.

8. Cainey, J.; Bowker, R.; Humphrey, L.; Murray, N. Assessing informal learning in an aquarium using pre- and post-visit drawings. Educ. Res. Eval. 2012, 18, 265-281. [CrossRef]

9. Cho, Y.; Lee, D. 'Love honey, hate honey bees': Reviving biophilia of elementary school students through environmental education program. Environ. Educ. Res. 2017, 24, 445-460. [CrossRef]

10. Dai, A. Learning from Children's Drawings of Nature; Katz, P., Ed.; Drawing for Science Education; Drawing for Science Education: An International Perspective; SensePublishers: Rotterdam, The Netherlands, 2017; pp. 73-86.

11. De Brito, M.; Jófili, Z.; dos Anjos, C. Ecological literacy-Preparing children for the twenty-first century. Early Child Dev. Care 2017, 187, 192-205. [CrossRef] 
12. Dentzau, M.W.; Gallard, A.J. Art to Capture Learning about the Longleaf Pine Ecosystem-Why a Picture Is Worth a Thousand Words; Mueller, M.P., Tippins, D.J., Eds.; EcoJustice, Citizen Science and Youth Activism: Situated Tensions for Science Education; Springer International Publishing: Cham, Switzerland, 2015; pp. 139-170.

13. Emmons, N.A.; Kelemen, D.A. Young children's acceptance of within-species variation: Implications for essentialism and teaching evolution. J. Exp. Child Psychol. 2015, 139, 148-160. [CrossRef] [PubMed]

14. Flowers, A.A.; Carroll, J.P.; Green, G.T.; Larson, L.R. Using art to assess environmental education outcomes. Environ. Educ. Res. 2015, 21, 846-864. [CrossRef]

15. Georgantopoulou, A.; Fragkiadaki, G.; Ravanis, K. Clouds as natural entities in preschool children's thought. Educ. J. Univ. Patras UNESCO Chair 2016, 3, 114-128.

16. Goodwin, T. Educating for Ecological Literacy. Am. Biol. Teach. 2016, 78, 287-291. [CrossRef]

17. Haring, U.; Sorin, R. The CID lens: Looking at children's drawings using content, interpretive, and developmental methods. Int. J. Arts Educ. 2014, 8, 15-29. [CrossRef]

18. Hsueh, Y.; Zhou, Z.; Su, G.; Lee, J.; Kitzmann, K. Science learning in early years: Effects of the Chinese television series Big Bird Looks at the World. Glob. Media China 2017, 2, 183-196. [CrossRef]

19. Izadkhah, Y.O.; Gibbs, L. A study of preschoolers' perceptions of earthquakes through drawing. Int. J. Disaster Risk Reduct. 2015, 14, 132-139. [CrossRef]

20. Kelemen, D.; Emmons, N.A.; Seston Schillaci, R.; Ganea, P.A. Young children can be taught basic natural selection using a picture-storybook intervention. Psychol. Sci. 2014, 25, 893-902. [CrossRef] [PubMed]

21. Linder, L.A.; Bratton, H.; Nguyen, A.; Parker, K.; Phinney, S. Comparison of good days and sick days of school-age children with cancer reflected through their drawings. Qual. Life Res. 2017, 26, 2729-2738. [CrossRef] [PubMed]

22. Loughland, T.; Reid, A.; Walker, K.; Petocz, P. Factors influencing young people's conceptions of environment. Environ. Educ. Res. 2003, 9, 3-19. [CrossRef]

23. Madden, L.; Liang, J. Young children's ideas about environment: Perspectives from three early childhood educational settings. Environ. Educ. Res. 2017, 23, 1055-1071. [CrossRef]

24. Malleus, E.; Kikas, E.; Marken, T. Kindergarten and primary school children's everyday, synthetic, and scientific concepts of clouds and rainfall. Res. Sci. Educ. 2017, 47, 539-558. [CrossRef]

25. Mouratidi, P.; Bonoti, F.; Leondari, A. Children's perceptions of illness and health: An analysis of drawings. Health Educ. J. 2016, 75, 434-447. [CrossRef]

26. Özsoy, S.; Ahi, B. Elementary School Students' Perceptions of the Future Environment through Artwork. Educ. Sci. 2014, 14, 1570-1582. [CrossRef]

27. Pitman, S.D.; Daniels, C.B.; Sutton, P.C. Characteristics associated with high and low levels of ecological literacy in a western society. Int. J. Sustain. Dev. World Ecol. 2017, 25, 227-237. [CrossRef]

28. Prokop, P.; Fančovičová, J.; Krajčovičová, A. Alternative conceptions about micro-organisms are influenced by experiences with disease in children. J. Biol. Educ. 2016, 50, 61-72. [CrossRef]

29. Prokop, P.; Tunnicliffe, S.D. "Disgusting" animals: Primary school children's attitudes and myths of bats and spiders. Eur. J. Math. Sci. Technol. Educ. 2008, 4, 87-97. [CrossRef]

30. Roberts, L.N. "I Have a Connection!": The Situated Sense-Making of an Elementary Student about the Role of Water in Modeled vs. Experienced Ecosystems; The University of Arizona: Tucson, AZ, USA, 2016.

31. Rybska, E.; Tunnicliffe, S.D.; Sajkowska, Z.A. Children's ideas about the internal structure of trees: Cross-age studies. J. Biol. Educ. 2017, 51, 375-390. [CrossRef]

32. Salmon, A.K.; Lucas, T. Exploring young children's conceptions about thinking. J. Res. Child. Educ. 2011, 25, 364-375. [CrossRef]

33. Sanz Ortega, O. Acercamiento a la comprensión del concepto de ser vivo en educación infantil. Ikastorratza E-Revista Didáctica 2015, 15, 6.

34. Snaddon, J.L.; Turner, E.C.; Foster, W.A. Children's perceptions of rainforest biodiversity: Which animals have the lion's share of environmental awareness? PLOS ONE 2008, 3, e2579. [CrossRef] [PubMed]

35. Stokas, D.; Strezou, E.; Malandrakis, G.; Papadopoulou, P. Greek primary school children's representations of the urban environment as seen through their drawings. Environ. Educ. Res. 2017, 23, 1088-1114. [CrossRef]

36. Tardif-Williams, C.Y.; Bosacki, S.L. Gender and Age Differences in Children's Perceptions of Self-Companion Animal Interactions Expressed through Drawings. Soc. Anim. 2017, 25, 77-97. 
37. Tsoi, K.H.; Chan, S.Y.; Lee, Y.C.; Ip, B.H.Y.; Cheang, C.C. Shark Conservation: An Educational Approach Based on Children's Knowledge and Perceptions toward Sharks. PLoS ONE 2016, 11, e0163406. [CrossRef] [PubMed]

38. Villarroel, J.D. Environmental judgment in early childhood and its relationship with the understanding of the concept of living beings. SpringerPlus 2013, 2, 87. [CrossRef] [PubMed]

39. Villarroel, J.D. Young Children's drawings of plant life: A study concerning the use of colours and its relationship with age. J. Biol. Educ. 2016, 50, 41-53. [CrossRef]

40. Villarroel, J.D.; Antón, Á.; Zuazagoitia, D.; Nuño, T. Young children's environmental judgement and its relationship with their understanding of the concept of living things. Environ. Socio-Econ. Stud. 2017, 5, 1-10. [CrossRef]

41. Villarroel, J.D.; Ortega, O.S. A study regarding the spontaneous use of geometric shapes in young children's drawings. Educ. Stud. Math. 2017, 94, 85-95. [CrossRef]

42. Villarroel, J.D.; Villanueva, X. A Study Regarding the Representation of the Sun in Young Children's Spontaneous Drawings. Soc. Sci. 2017, 6, 95. [CrossRef]

(C) 2018 by the authors. Licensee MDPI, Basel, Switzerland. This article is an open access article distributed under the terms and conditions of the Creative Commons Attribution (CC BY) license (http:/ / creativecommons.org/licenses/by/4.0/). 